\title{
Optimal management of post-traumatic radioulnar synostosis
}

This article was published in the following Dove Press journal: Orthopedic Research and Reviews

\author{
A Lee Osterman' \\ Melissa S Arief \\ 'Department of Orthopaedic \& \\ Hand Surgery, Philadelphia Hand to \\ Shoulder Center, Thomas Jefferson \\ University, Philadelphia, PA, ${ }^{2}$ KSF \\ Orthopaedic Center, Houston, TX, \\ USA
}

Correspondence: Melissa S Arief ${ }^{2}$ KSF Orthopaedic Center, 17270 Red Oak Drive, Suite 200, Houston, TX 77090, USA

Tel + I 9086428909

Fax +I 28I 4406960

Email melissa.arief@gmail.com

\begin{abstract}
Post-traumatic radioulnar synostosis is a rare complication after forearm or elbow injury that can result in loss of motion and significant disability. Risk factors include aspects of the initial trauma and of the surgical treatment of that trauma. Surgical intervention for synostosis is the standard of care and is determined based on the location of the bony bridge. Surgical timing is recommended between 6 months and 2 years with recent advocacy for the 6- to 12-month period after radiographs demonstrate bony maturation but early enough to prevent further stiffness and contractures. For most types of synostosis, surgical resection with interposition graft is recommended. The types of materials used include synthetic, allograft, and vascularized and non-vascularized materials, but currently there is no consensus on which is the most preferable. Adjuvant therapy is not considered necessary for all cases but can be beneficial in patients with high risk factors such as recurrence or traumatic brain injury. Postoperative rehabilitation should be performed early to maintain range of motion.
\end{abstract}

Keywords: radioulnar synostosis, forearm fracture, rotatory forearm motion, heterotopic bone forearm

\section{Introduction}

Post-traumatic radioulnar synostosis is a rare complication seen after fractures of the forearm and elbow. ${ }^{1}$ The synostosis can occur anywhere along the forearm leading to loss of forearm rotation and functional impairment. It can occur after both nonsurgical and surgical treatment. Reports have estimated the incidence to be from 0 to $9.4 \%$ of patients after treatment of one or both bone fractures of the forearm with open reduction and internal fixation with plating. ${ }^{2-5}$

Risk factors include a high degree of soft tissue injury, comminuted fractures, both bones at the same level, Monteggia fractures, surgical delay, traumatic brain injury, and prolonged immobilization with late rehabilitation. ${ }^{2-4,6-9}$ There may be an association with open fractures; however, this could simply just reflect the degree of soft tissue injury. ${ }^{4}$ Surgery can also increase the likelihood of a synostosis. This is mostly due to surgical technique that causes disruption of the interosseous membrane, bone graft or hardware in the interosseous space, and iatrogenic trauma to the soft tissues..$^{3,4,10-12}$

\section{Optimization of initial treatment}

Multiple factors can lead to the formation of a synostosis, and optimization of initial treatment can minimize the risk of development. Surgical management of both bone fractures should be approached via two incisions within a reasonable period of time. ${ }^{4}$ Injury to the interosseous membrane should be avoided. ${ }^{10,11}$ The interosseous space submit your manuscript 
should be carefully cleared of all bone graft and bony fragments. Care should be taken to place appropriately length screws or fixator pins that do not extend into the interosseous space or violate the opposite bone., ${ }^{412}$

\section{Classification}

An initial classification was proposed by Vince and Miller, ${ }^{4}$ who used the anatomic location of the synostosis along the length of the forearm (Figure 1). Type I consisted of a synostosis within the distal intra-articular portion of the radius and ulna. Type II occurred in the middle third and type III in the proximal third of the forearm. This classification was later modified by Jupiter and Ring ${ }^{5}$ by sub-classifying the proximal third synostosis into different types. Type IIIA is at the level of or distal to the bicipital tuberosity and type IIIB is present at the radial head. Type IIIC is a continuation of heterotopic bone from the elbow or distal humerus. These classifications are useful to help guide surgical approaches.

\section{Management}

Surgical management is the gold standard to improve forearm rotation and function particularly in patients with unacceptable functional loss of motion. It is important that the patient be capable of committing to post-operative therapy. A case example is shown in Figure 2. Conservative management is reserved for patients with a functional arc of motion, low-demand patients with high comorbidities who are unable to tolerate further procedures, and patients unable to accept the risks of surgery. ${ }^{9}$

\section{Surgical timing}

There is no consensus on optimal timing for surgery. While there are multiple guidelines based on radiographic imaging, bone scans, and serum alkaline phosphatase levels, none is considered to be the standard. While it is advisable to avoid early surgery due to the high risk of recurrence, there are no rigid waiting periods. There are reports of surgery prior to 6 months with good results ${ }^{13,14}$ but in general the consensus is between 6 months and 2 years. ${ }^{1,4,8,15,16}$ Historically, the best results occur after maturation of bone usually between 1 and 2 years after injury. ${ }^{4,8}$ More recent papers suggest that resection between 6 and 12 months yields good overall results without increased risk for recurrence if performed in patients with radiographic bony maturation..$^{5,13,15,26}$ Early resection in

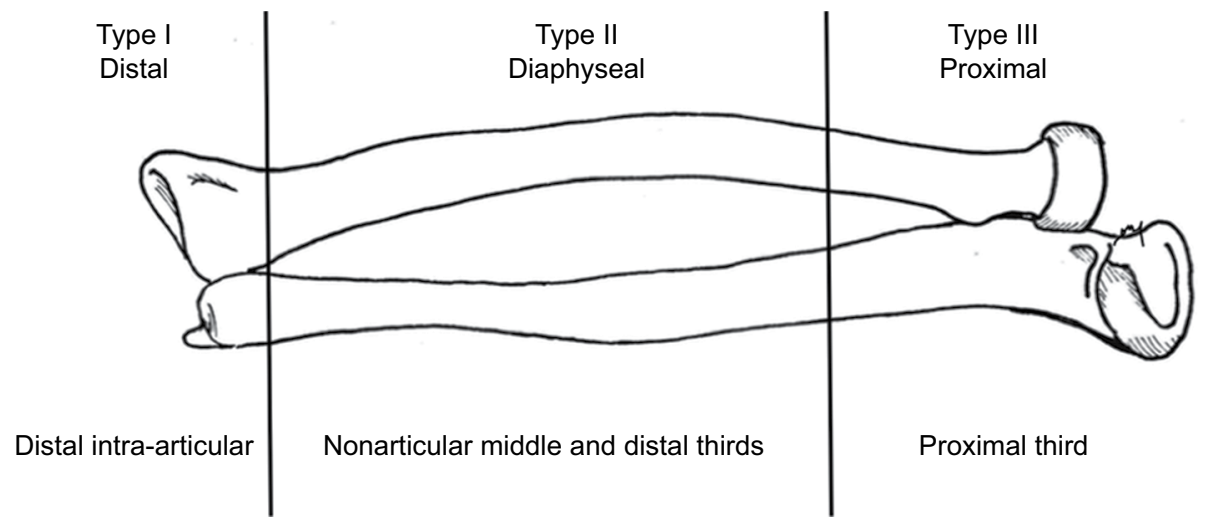

Figure I Illustration of the Vince and Miller classification with type I, which involves the distal intra-articular aspect of the forearm; type II is the middle and distal third of the forearm; and type III is based on the length of the ulna and is the proximal one third of the forearm.

Note: Courtesy of Melissa Arief, MD.

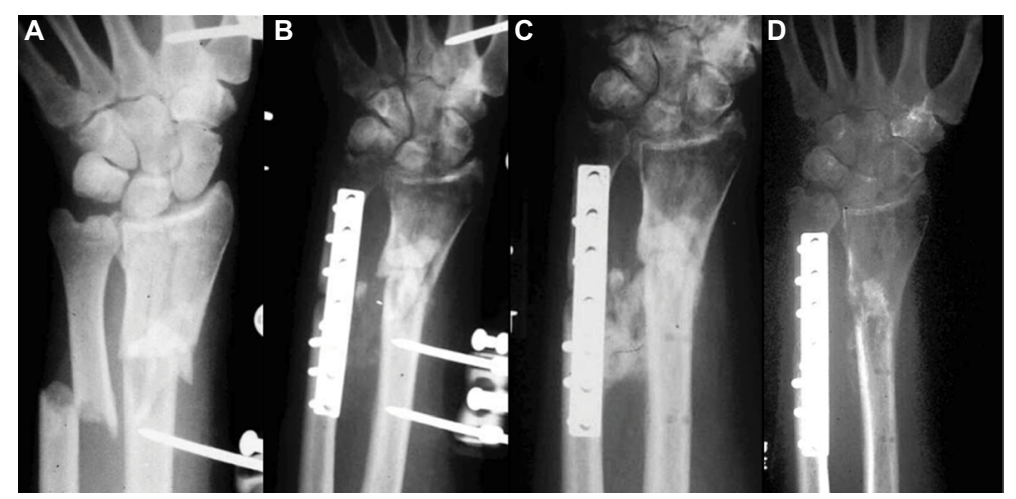

Figure 2 (A) Patient sustained open fractures of both bones and was placed in an external fixator; (B) early formation of synostosis; (C) fully mature synostosis; and (D) after successful excision of the synostosis.

Note: Courtesy of Thomas W Wright, MD. 
these patients has the added benefit of earlier restoration of joint motion and prevention of soft tissue contractures.

\section{Surgical options based on classification}

The classification based on location helps guide overall treatment. Hastings and Graham ${ }^{17}$ described this summary of treatment (Figure 3). Type I can be treated with Sauvé -Kapandji procedure if the distal radioulnar joint (DRUJ) has degenerative changes and the synostosis is located under the pronator quadratus and Darrach procedure if located at the DRUJ. In type II and type IIIA, treatment is usually excision of the synostosis with or without the placement of an interposition graft. Type IIIB can be treated with radial head excision or replacement. Type IIIC can be treated by arthroplasty.

\section{Resection with/without interposition}

In type II and IIIA synostosis, the aim of treatment is complete surgical resection. The use of an interposition material either biologic or synthetic continues to be controversial. Most reports are small cohort studies or case reports describing various techniques and surgical options with good results. Interposition is thought to prevent recurrence and minimize scar formation. The different options for interposition include synthetic (eg, silicone, polyethylene, bone wax), allograft (eg, fascia, muscle), and vascularized and non-vascularized autogenous material (eg, fascia lata, adipofascial flaps). . $^{1,5,8,9,16,18-20}$ The procedure itself involves full resection of the synostosis and then placement of the graft around the radius or ulna, which is then secured with absorbable sutures.

Most reports using various techniques and materials have offered good results. Jupiter and Ring ${ }^{5}$ reported eight cases treated with free fat flap and ten cases with no interposition. No adjuvant therapy was included. Results were functionally equivalent.
Bell and Benger ${ }^{18}$ offered a series of three patients treated with vascularized anconeus muscle interposition. At follow-up prono-supination results yielded arcs of $100^{\circ}$, $110^{\circ}$, and $150^{\circ}$.

Yong-Hing and Tchang, ${ }^{21}$ Kawaguchi et al, ${ }^{22}$ and Muramatsu et $\mathrm{al}^{23}$ each presented two cases treated with free vascularized fat transplant with good results.

Sugimoto et $\mathrm{al}^{24}$ reported a case of a vascularized fat flap form the distal third of the forearm with $10^{\circ}$ of pronation and $55^{\circ}$ of supination at 1 year. Sonderegger et a ${ }^{25}$ reported a series in seven patients using a vascularized adipofascial flap in these patients with range of motion (ROM) of $70^{\circ}$ pronation and $70^{\circ}$ supination.

Friedrich et $\mathrm{al}^{16}$ reported the use of fascia lata graft in 13 cases with a preference for allograft due to donor site morbidity. At 30-month follow-up, there were two moderate, two good, and nine excellent results.

Failla et $\mathrm{al}^{8}$ offered a series of 20 synostosis with 12 treated with interposition. Of those treated, eight were treated with silicone gum leaf; muscle in two; fat, fascia, polyethylene, and silicone block in one. The results were excellent in four cases, good in three, moderate in four and poor in nine. Overall results demonstrated that biologic interposition material yielded moderate to poor results; however, the use of interpositional material was more beneficial then isolated resection.

Recently, Pfanner et a ${ }^{26}$ presented two cases treated with interposition with allogenic fascia lata graft with full restoration of ROM and no recurrence at 2 years.

In patients for whom a removal of the proximal synostosis is not possible, Kamineni et $\mathrm{al}^{27}$ described a technique in which $1 \mathrm{~cm}$ of the radial shaft is excised, by passing the synostosis and creating a pseudoarthrosis. Of those patients, two were excellent, four were good, and one was fair.

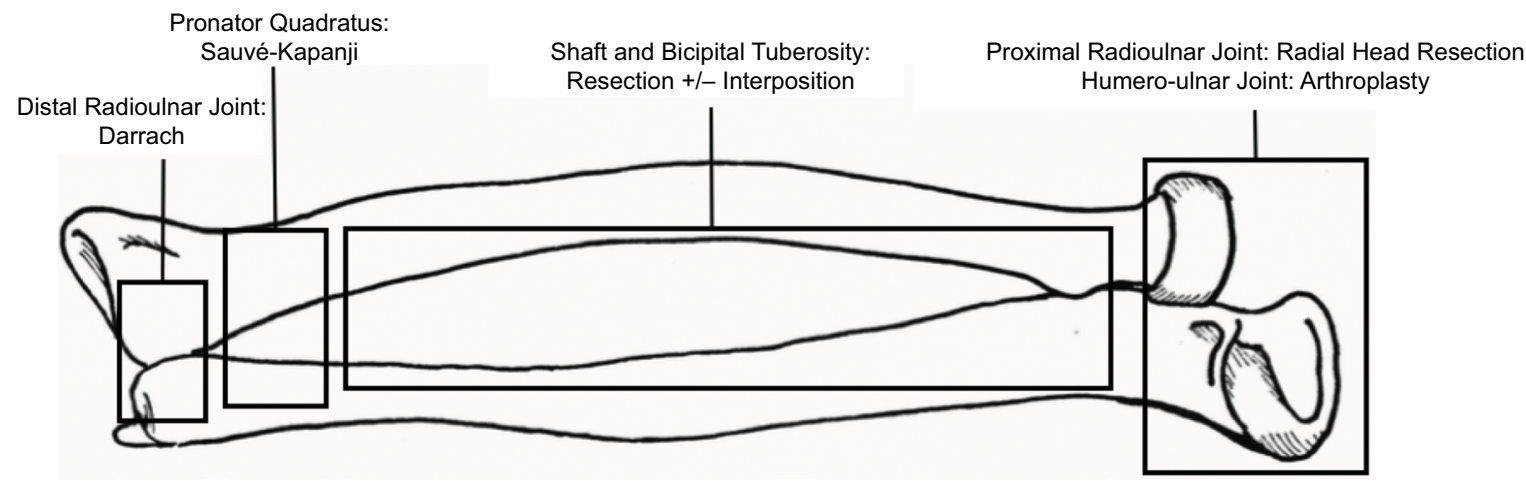

Figure 3 Hastings and Graham classification. Note: Courtesy of Melissa Arief, MD. 
In summary, there is no final consensus regarding the benefit of interposition following synostosis resection or the type of material to be used. The senior author does not routinely use any interposition material. However, if a graft is to be used, there is an overall preference for an interposition with fascia lata allograft providing good results.

\section{Adjuvant therapy}

Adjuvant therapy with prophylactic treatment methods is another possibility for preventing heterotopic bone postoperatively. Most of the benefits of adjuvant therapies including non-steroidal anti-inflammatory drugs (NSAIDs) and lowdose radiation have been described in prevention of heterotopic bone formation in the hip. However, there have been only limited studies demonstrating the effects in prevention of radioulnar synostosis recurrence.

Bisphosphonates, on the other hand, have not been shown to be efficacious in preventing calcification in total hip replacements (THR). ${ }^{28}$

The use of indomethacin has proven to be effective in preventing heterotopic ossification in the hip after THR at approximately $75 \mathrm{mg}$ per day ( $25 \mathrm{mg}$ three times daily) in multiple studies..$^{29-32}$ There has been some limited evidence to support this use in synostosis patients such as the case report written by Lytle et $\mathrm{a}^{33}$ in which the patient was treated with dermal silicone sheet implant and indomethacin. The patient had full pronation and near normal supination with no recurrence at 1 year postoperatively. Pfanner et $\mathrm{al}^{26}$ reported two cases treated with resection and fascia lata allograft with 2 months of Celebrex postoperatively. They reported full ROM and no recurrence at 2 years. On the other hand, others do consider that in the post-traumatic period indomethacin has been shown to impair fracture healing in animal studies, ${ }^{34,35}$ which makes it less desirable for acute prevention. In addition, Viola and Hanel conducted a study on elbow stiffness and found that only two of the 15 patients actually took the medication and it had no overall effect on the outcome in the end. ${ }^{36}$

Low-dose radiation has been proven to be effective in preventing calcification after THR and has been reported to have good results in the prevention of recurrence of synostosis. Cullen et $\mathrm{al}^{37}$ reported a series of four patients treated with a single treatment of radiation of $800 \mathrm{cGy}$ within 4 days of resection with no complications or recurrence. Abrams et $\mathrm{al}^{38}$ reported two cases, one treated with $700 \mathrm{cGy}$ in one dose and another treated with a total of 1000 cGy divided over four daily doses. Neither patient had recurrence at 21 and 43 months, respectively. The most concerning risk regarding the use of radiation is the risk of radiation-induced sarcoma $\mathrm{a}^{39}$ and should be kept in mind when considering radiation therapy particularly for a non-life threatening condition.

Routine use of radiation or indomethacin is still not recommended for every case. Most consider it useful for patients at high risk for developing a recurrence. Therefore, the decision to irradiate or treat with NSAIDs should be made on an individual basis.

\section{Rehabilitation}

There is an overall agreement that early and intensive rehabilitation is necessary but there is no consensus to any particular protocol. ${ }^{9}$ Postoperatively, bracing can be started 1 or 2 weeks after surgery or can be performed immediately to maintain motion. Friedrich et $\mathrm{a}^{16}$ recommended static splinting in full supination with the elbow at $90^{\circ}$ and the wrist extended at $30^{\circ}$ during the day and then alternating at night in the first 2 weeks, splinting between maximal pronation and supination. Hanel et $\mathrm{al}^{40}$ recommend a removable splint with the elbow at $90^{\circ}$ and the wrist in neutral with splint removal every hour for ROM exercises on the first postoperative day. Then conversion to a wrist-only splint during the initial post operative week.

\section{Recurrence}

The risk of recurrence after primary resection is reported between 6 and 35\% with a higher incidence in those with significant soft tissue injury and associated head injury. ${ }^{4,5,8}$ The patients should be well counseled that with any surgery that is performed there is always the possibility of recurrence. Should the patient have high-risk factors such as history of head trauma, heterotopic ossification, or multiple recurrences, other prophylactic modalities should be considered.

\section{Authors' experience}

In our series, 23 patients were followed up for more than 1 year. The patients were treated with either free fat flaps or no interposition graft. The results support the results of Jupiter and Ring, ${ }^{5}$ which documented a successful outcome in their $17 / 18$ patients using the two same techniques. In our series, free fat flaps were used early in this series but later abandoned in favor of no interposition material. A total of $87 \%$ of the patients regained and maintained $75 \%$ of rotatory motion postoperatively. Our timing has moved away from the older tenets of bone trabecular maturity, quiet bone scans, and alkaline phosphatase readings to an earlier intervention when there are stable soft tissues, fracture healing, and neurologic status. This is usually between 4 and 6 months. We always use CT localization of the synostosis, more limited incisions, 
and early intensive therapy. In our current algorithm, such interventions have generally replaced using radiation and other interpositional techniques.

\section{Conclusion}

Post-traumatic radioulnar synostosis is a rare complication following forearm or elbow injury. It typically results in loss of motion of pronation and supination causing significant disability. Treatment in the literature is mostly level IV with small cohort studies and case reports. Surgical intervention is the standard of care and is determined by the classification based on location. Surgical timing is recommended after 4-6 months to allow for bony maturation of the synostosis. For type II and type IIIA, surgical resection with interposition graft is recommended, although there is no consensus on the graft material being used. The authors' preferred technique is early intervention with no interpositional material. Adjuvant therapy is not considered necessary for all cases but can be beneficial in patients with high-risk factors such as recurrence or traumatic brain injury. Finally, early and intensive postoperative rehabilitation is essential to maintain ROM.

\section{Disclosure}

The authors report no conflicts of interest in this work.

\section{References}

1. Dohn P, Khiami F, Rolland E, Goubier JN. Adult post-traumatic radioulnar synostosis. Orthop Traumatol Surg Res. 2012;98(6):709-714.

2. Anderson LD, Sisk D, Tooms RE, Park WI 3rd. Compression-plate fixation in acute diaphyseal fractures of the radius and ulna. $J$ Bone Joint Surg Am. 1975;57(3):287-297.

3. Bauer G, Arand M, Mutschler W. Post-traumatic radioulnar synostosis after forearm fracture osteosynthesis. Arch Orthop Trauma Surg. 1991;110(3):142-145.

4. Vince KG, Miller JE. Cross-union complicating fracture of the forearm. Part II: children. J Bone Joint Surg Am. 1987;69(5):654-661.

5. Jupiter JB, Ring D. Operative treatment of post-traumatic proximal radioulnar synostosis. J Bone Joint Surg Am. 1998;80(2):248-257.

6. Stern PJ, Drury WJ. Complications of plate fixation of forearm fractures. Clin Orthop Relat Res. 1983;(175):25-29.

7. Garland DE, Dowling V. Forearm fractures in the head-injured adult. Clin Orthop Relat Res. 1983;(176):190-196.

8. Failla JM, Amadio PC, Morrey BF. Post-traumatic proximal radioulnar synostosis. Results of surgical treatment. J Bone Joint Surg Am. 1989;71(8):1208-1213.

9. Bergeron SG, Desy NM, Bernstein M, Harvey EJ. Management of posttraumatic radioulnar synostosis. J Am Acad Orthop Surg. 2012;20(7):450-458.

10. Botting TD. Posttraumatic radio-ulna cross union. J Trauma. 1970;10(1):16-24.

11. Ayllon-Garcia A, Davies AW, Deliss L. Radio-ulnar synostosis following external fixation. $J$ Hand Surg Br. 1993;18(5):592-594.

12. Wright RR, Schmeling GJ, Schwab JP. The necessity of acute bone grafting in diaphyseal forearm fractures: a retrospective review. J Orthop Trauma. 1997;11(4):288-294.
13. Sotereanos DG, Sarris I, Chou KH. Radioulnar synostosis after the twoincision biceps repair: a standardized treatment protocol. J Shoulder Elbow Surg. 2004;13(4):448-453.

14. Beingessner DM, Patterson SD, King GJ. Early excision of heterotopic bone in the forearm. J Hand Surg Am. 2000;25(3):483-488.

15. Watson FM Jr, Eaton RG. Post-traumatic radio-ulnar synostosis. J Trauma. 1978;18(6):467-468.

16. Friedrich JB, Hanel DP, Chilcote H, Katolik LI. The use of tensor fascia lata interposition grafts for the treatment of posttraumatic radioulnar synostosis. J Hand Surg Am. 2006;31(5):785-793.

17. Hastings $\mathrm{H}$ 2nd, Graham TJ. The classification and treatment of heterotopic ossification about the elbow and forearm. Hand Clin. 1994;10(3):417-437.

18. Bell SN, Benger D. Management of radioulnar synostosis with mobilization, anconeus interposition, and a forearm rotation assist splint. J Shoulder Elbow Surg. 1999;8(6):621-624.

19. Fernandez DL, Joneschild E. "Wrap around" pedicled muscle flaps for the treatment of recurrent forearm synostosis. Tech Hand Up Extrem Surg. 2004;8(2):102-109.

20. Jones NF, Esmail A, Shin EK. Treatment of radioulnar synostosis by radical excision and interposition of a radial forearm adipofascial flap. J Hand Surg Am. 2004;29(6):1143-1147.

21. Yong-Hing K, Tchang SP. Traumatic radio-ulnar synostosis treated by excision and a free fat transplant. A report of two cases. $J$ Bone Joint Surg Br. 1983;65(4):433-435.

22. Kawaguchi S, Kitamura M, Usui M. Proximal radioulnar synostosis treated with a free vascularised fascio-fat graft--report of two cases. Hand Surg. 2000;5(2):161-164.

23. Muramatsu K, Ihara K, Shigetomi M, Kimura K, Kurokawa Y, Kawai S. Posttraumatic radioulnar synostosis treated with a free vascularized fat transplant and dynamic splint: a report of two cases. J Orthop Trauma. 2004;18(1):48-52.

24. Sugimoto M, Masada K, Ohno H, Hosoya T. Treatment of traumatic radioulnar synostosis by excision, with interposition of a posterior interosseous island forearm flap. J Hand Surg Br. 1996;21(3):393-395.

25. Sonderegger J, Gidwani S, Ross M. Preventing recurrence of radioulnar synostosis with pedicled adipofascial flaps. J Hand Surg Eur Vol. 2012;37(3):244-250.

26. Pfanner S, Bigazzi P, Casini C, De Angelis C, Ceruso M. Surgical treatment of posttraumatic radioulnar synostosis. Case Rep Orthop. 2016;2016:5956304.

27. Kamineni S, Maritz NG, Morrey BF. Proximal radial resection for posttraumatic radioulnar synostosis: a new technique to improve forearm rotation. J Bone Joint Surg Am. 2002;84-A(5):745-751.

28. Thomas BJ, Amstutz HC. Results of the administration of diphosphonate for the prevention of heterotopic ossification after total hip arthroplasty. J Bone Joint Sur Am. 1985;67(3):400-403.

29. Fransen M, HIPAID Management Committee of the HIPAID Collaborative Group. Preventing chronic ectopic bone-related pain and disability after hip replacement surgery with perioperative ibuprofen. A multicenter, randomized, double-blind, placebo-controlled trial (HIPAID). Control Clin Trials. 2004;25(2):223-233.

30. Kienapfel H, Koller M, Wüst A, et al. Prevention of heterotopic bone formation after total hip arthroplasty: a prospective randomised study comparing postoperative radiation therapy with indomethacin medication. Arch Orthop Trauma Surg. 1999;119(5-6):296-302.

31. Vavken P, Castellani L, Sculco TP. Prophylaxis of heterotopic ossification of the hip: systematic review and meta-analysis. Clin Orthop Relat Res. 2009;467(12):3283-3289.

32. Ritter MA, Gioe TJ. The effect of indomethacin on para-articular ectopic ossification following total hip arthroplasty. Clinical Orthop Relat Res. 1982;(167):113-117.

33. Lytle IF, Chung KC. Prevention of recurrent radioulnar heterotopic ossification by combined indomethacin and a dermal/silicone sheet implant: case report. J Hand Surg Am. 2009;34(1):49-53.

34. Sudmann E, Hagen T. Indomethacin-induced delayed fracture healing. Arch Orthop Unfallchir. 1976;85(2):151-154. 
35. Allen HL, Wase A, Bear WT. Indomethacin and aspirin: effect of nonsteroidal anti-inflammatory agents on the rate of fracture repair in the rat. Acta Orthop Scand. 1980;51(4):595-600.

36. Viola RW, Hanel DP. Early "simple" release of posttraumatic elbow contracture associated with heterotopic ossification. J Hand Surg Am. 1999;24(2):370-380.

37. Cullen JP, Pellegrini VD Jr, Miller RJ, Jones JA. Treatment of traumatic radioulnar synostosis by excision and postoperative low-dose irradiation. J Hand Surg Am. 1994;19(3):394-401.
38. Abrams RA, Simmons BP, Brown RA, Botte MJ. Treatment of posttraumatic radioulnar synostosis with excision and low-dose radiation. J Hand Surg Am. 1993;18(4):703-707.

39. Samartzis D, Nishi N, Cologne J, et al. Ionizing radiation exposure and the development of soft-tissue sarcomas in atomic-bomb survivors. $J$ Bone Joint Surg Am. 2013;95(3):222-229.

40. Hanel DP, Pfaeffle HJ, Ayalla A. Management of posttraumatic metadiaphyseal radioulnar synostosis. Hand Clin. 2007;23(2):227-234, vi-vii.

\section{Publish your work in this journal}

Orthopedic Research and Reviews is an international, peer-reviewed, open access journal that focusing on the patho-physiology of the musculoskeletal system, trauma, surgery and other corrective interventions to restore mobility and function. Advances in new technologies, materials, techniques and pharmacological agents are particularly welcome. The manuscript management system is completely online and includes a very quick and fair peer-review system, which is all easy to use. Visit http://www.dovepress.com/testimonials.php to read real quotes from published authors. 